\title{
ОСОБЕННОСТИ ИНДЕКСА МАССЫ ТЕЛА И ХАРАКТЕРА РАСПРЕДЕЛЕНИЯ ЖИРОВОЙ ТКАНИ У БОЛЬНЫХ С ФОЛЛИКУЛЯРНЫМИ АДЕНОМАМИ ЩИТОВИДНОЙ ЖЕЛЕЗЫ
}

\author{
${ }^{1}$ Халимова А.С., ${ }^{1}$ Квиткова Л.В.
}

'ФГБОУ ВО Кемеровский государственный медицинский университет Министерства здравоохранения Российской Федерации, кафедра факультетской терапии, профессиональных болезней и эндокринологии, г. Кемерово.

ЦЕЛЬ: оценить распространенность ожирения и его вариантов среди лиц с фолликулярными аденомами (ФА) щитовидной железы (ЩЖ) и без патологии ЩЖ.

МАТЕРИАЛЫ И МЕТОДЫ: в исследовании участвовали 107 женщин, средний возраст 53 года (42;60) с подтвержденным по гистологическому исследованию биоптата диагнозом ФА ЩЖ. Контрольная группа включала 46 женщин, средний возраст 53 года (42;57) без патологии ЩЖ и тяжелой соматической патологии.У пациентов оценивались антропометрические показатели (рост, вес, ИМТ, ОТ, ОТ/ОБ), показатели крови: тиреотропный гормон (ТТГ), свободный тироксин (св. Т4) методом иммуноферментного анализа (ИФА), УЗИ ЩЖ. Референсные значения - ИМТ 18,5-25 кг/м² - нормальная масса тела, ОТ $\leq 80$ см,

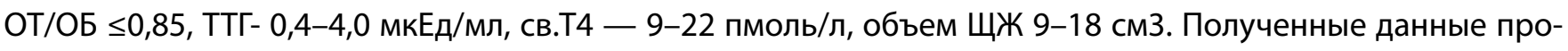
анализированы в Statistica 6.1. Статистически значимыми считали различия при р<0,05.

PЕзУЛЬТАТЫ: у всех пациентов сравниваемых групп, как с ФА ЩЖ, так и в контрольной, был подтвержден клинически и лабораторно эутиреоз. ИМТ у большинства пациентов обеих групп был или повышен, или соответствовал ожирению. Данные показатели в группе пациентов с ФА ЩЖ составили соответственно: 30,8\% и 38,4\%, в группе контроля - 30,4\% ( $p=0,97)$ и 41,3\% ( $p=0,38)$. Средний ИМТ в группе пациентов

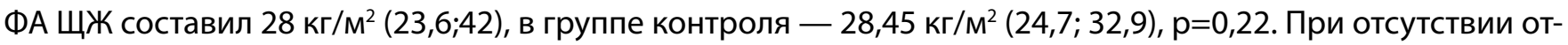
личий по ИМТ характер распределения жировой ткани в обеих группах имел особенности. Так, при сравнительной оценке ОТ, ОТ/ОБ установлено, что показатель ОТ>80 см имели свыше 2/3 (73,8\%) пациентов с ФА ЩЖ, в группе контроля - 15,2\%, p=0,001. Индекс ОТ/ОБ>0,85 среди пациентов с ФА ЩЖ встречался с частотой 61,6\%, в группе контроля - 10,9\%, p=0,001. Среди пациентов с ФА ЩЖ средний показатель ОТ составил 92 см (80;102), ОТ/ОБ 0,862 (0,796;0,9), в контрольной группе данные показатели составили соответственно ОТ - 77 см (74;80), p=0,00000; ОТ/ОБ - 0,762 (0,731;0,809), p=0,00000. Обращает внимание, что среди лиц с ФА ЩЖ патологическое увеличение ОТ и ОТ/ОБ нередко встречалось у лиц с нормальным ИМТ: соответственно 35,5\% и 24,2\%. Частота данных показателей увеличивалась по мере возрастания ИМТ: при избыточном ИМТ соответственно 96,5\% и 81,8\%, при ожирении - 100\% и 92,6\%. В контрольной группе у лиц с нормальным ИМТ данные показатели были в норме, но при избыточном ИМТ частота показателей увеличилась и составила соответственно 7,1\% (p=0,006) и 7,1\% (p=0,02), при ожирении - 31,5\% $(p=0,02)$ и 21\% (p=0,008), однако показатели были более низкими, чем среди лиц с ФА ЩЖ.

\section{ВЫводы:}

1. Среди пациентов с ФА ЩЖ большинство имеют избыточную массу тела - 30,8\% или ожирение $38,4 \%$.

2. При ФА ЩЖ тип ожирения носит преимущественно висцеральный характер: ОТ >80 см у 73,8\%, индекс ОТ/ОБ >0,85 у 61,6\% пациентов.

3. Признаки висцерального ожирения (высокие показатели ОТ и ОТ/ОБ) среди лиц с ФА ЩЖ встречаются у каждого четвертого пациента с нормальным ИМТ. При увеличении ИМТ частота висцерального ожирения увеличивается.

4. Висцеральный тип ожирения нуждается в своевременной диагностике с целью возможной первичной профилактики формирования ФА ЩЖ. 